\title{
The real value to the mining industry of leading-practice waste management
}

\section{G.M. Bentel Consultant, Australia}

\section{Introduction}

Mining wastes - waste rock, process tailings, and other mining by-products — have little beneficial use or value. If not managed well, some wastes can leave an enduring threat of serious health and/or environmental harm, and hence good waste management practice can significantly increase both capital and operating costs.

Some mining waste can cause serious health and environment issues, and therefore responsible waste management is a key attribute of sustainable mining. When poor or irresponsible waste management is discovered and publicised through the media, the responsible company can suffer serious detrimental consequences through public outrage and loss of stakeholder and shareholder confidence and support.

While not exactly a waste management issue, the public (including President Obama) and shareholder reaction (Figure 1) to the BP Deepwater Horizon incident that resulted in the loss of 11 lives, 17 injured, and that continues to wreak untold environmental damage, illustrates society's perception of the social and financial implications of a catastrophic environmental incident.

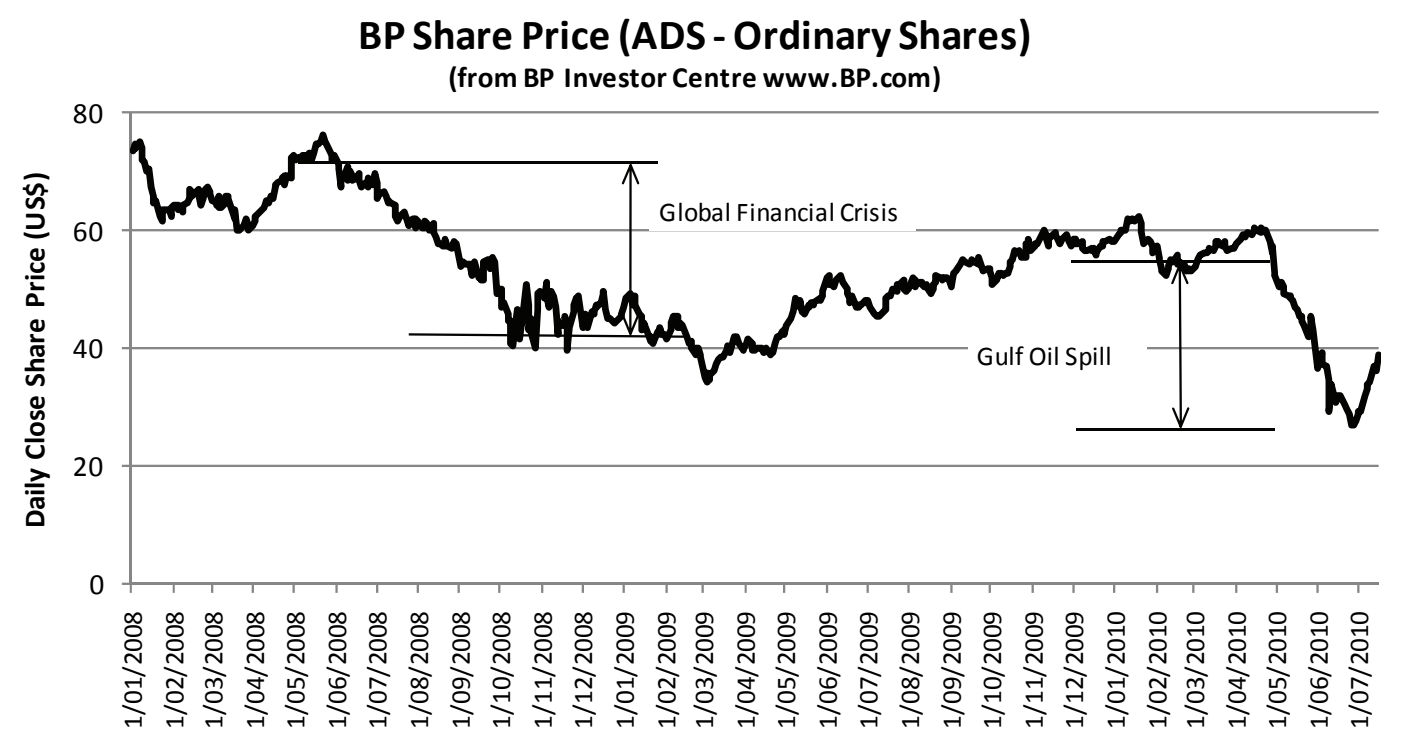

Figure 1 BP Share Price - 1 January 2008 to 1 July 2010

In addition to significant coverage of the BP Gulf incident, the Weekend Australian Financial Review, 17-18 July 2010 also included the following mining related news:

Consternation as Garret pauses LNG industry (Page 13)

“...the letter that the federal Environment Minister sent to energy companies BG Group and Santos last week, in which he demands more information about the long-term environmental impact of their proposed coal seam gas projects in Queensland, is causing widespread ramifications and consternation.

The letter puts a question mark over the immediate future of the more than \$35 billion in investment. It is causing political anxiety at both a state and federal level, and igniting debate over what the environmental footprint the massive liquefied natural gas industry will eventually leave behind." 
Water pollution halts UCG projects (Page 17)

“.... Cougar placed its shares in a trading halt after Queensland's Department of Environmental and Resource Management closed down the company's trial plant near Kingaroy on Friday."

Three Held for acid leak (Page 20)

"Zijin Mining group, China's largest gold producer, said on Friday three managers were detained for an acid leak that poisoned tonnes of fish at its biggest copper asset. The July 3 acid leak at the Zijinshan copper plant poisoned 1890 tonnes of fish at a waterway near Shanghang County in Fujian province."

While there may be significant financial implications associated with the potential long-term impacts of mining on health and the environment, it is really society's attitude towards the social and environmental impacts from mining that has changed dramatically over the last two decades. Only 20 to 30 years ago, mining deaths, serious environmental and/or social incidents and other mining related issues were tolerated and accepted, because mining was considered a tough and risky business - not for softies.

Today, neither society nor the mining industry accepts that mining is either dangerous or harmful. The mining industry aspires to sustainable development, i.e. continued access to economically viable resources anywhere in the world, through leading practices that seek to improve the quality of life of all stakeholders, while ensuring the continued wellbeing of affected communities and the environment.

It is the licence to operate, i.e. society's permission to develop more and larger mines that will be significantly challenged by any further major mining environmental incidents that undermine the industry's reputation. One just has to imagine how complex, difficult, costly and challenging it will be for BP, or any major oil company, to get approval to drill a new oil well off the east coast of the USA.

Some mining wastes are capable of causing serious long-term health and environmental issues, particularly after closure when a mining operation's risk management controls may be switched off. Therefore, it is in the licence to operate that the real value of leading practice waste management lies, alongside the other key health, safety, environmental and social/community challenges facing the mining industry.

\section{The value of licence to operate to the mining industry}

Until fairly recently, a licence to operate was the mechanism by which mining companies were required to comply with regulatory and legal obligations - in other words the operating licence or operating permit. Having experienced significant fall-out from serious environmental incidents, and with growing community and stakeholder sentiment that mining companies had ethical and social obligations that reach far beyond permit compliance, the mining industry realised that in order to remain sustainable, the licence to operate needed to include the key elements of sustainable development, i.e.:

- Economic considerations - growth of mineral resource/ore reserves; shareholder return on investment; low costs.

- Environmental considerations - operating and closure policies and standards inclusive of the challenges associated with climate change, water conservation and waste management.

- Social and community considerations - the ongoing health and wellbeing of the people and stakeholder communities potentially impacted by each mining operation.

The mining industry also recognised that reputation, trust, honesty and a win-win approach have large roles to play in garnering support for a licence to operate, particularly when engaging potentially antagonistic communities, environmental groups and social and environmental activists. Hence, the licence to operate is also strongly influenced by:

- Stakeholder engagement - the need to engage stakeholders in all aspects of the development, operation and closure of a project.

- Transparency - the need to measure and report all material environmental, safety, health, social and economic operational aspects truthfully and openly so that nothing is hidden from the stakeholders and the general public. 
- Ethical behaviour - the need for a code of conduct to embed ethical behaviour into an organisation at all times, including the obligation to apply the same health, environment, safety and community standards irrespective of where an operation may be established.

The present day concept of licence to operate has probably become a mining company's most valuable asset, alongside its minerals resource and ore reserves. Without a healthy licence to operate, a mining company cannot compete effectively, and hence it cannot grow its minerals resource base. It may also find it difficult to maintain profitability when its ore reserves begin to deplete and it loses customer and shareholder support (and share value), either becoming a take-over target or starting down the path to closure.

The value of the licence to operate is summarised well in the introduction to BHP Billiton's 'Our Sustainability Framework' (BHP Billiton, 2010):

\begin{abstract}
"For BHP Billiton, sustainable development is about ensuring our business remains viable and contributes lasting benefits to society through the consideration of social, environmental, ethical and economic aspects in all that we do. Working through complex operational issues associated with our operations has highlighted environmental and social performance as a critical success factor for the Company. We are well aware of the costs of getting it wrong; but more importantly, we recognise the value that can be created by getting it right. Consequently, we adopt a holistic approach to business strategy, seeking to realise value for our stakeholders through a sustainable business philosophy."
\end{abstract}

\title{
3 How can waste management impact the licence to operate?
}

Some areas where waste management can have major impacts on licence to operate include:

1. Unresolved legacy issues - there are many examples where poor tailings and waste management practiced by previous generations, compounded by inadequate closure planning and provisioning, have resulted in an enormous financial impost on the current generation of mining companies. In addition to the financial impost, the reputational element remaining from seriously damaged sites never goes away, potentially impacting future approvals and licence compliance levels.

2. Early or sudden closure - the promise to achieve the environmental and social elements of sustainability endures only as long as a mining company is profitable. Sudden or early closure can happen at any mine, even if only as a result of commodity price cycles. When the financials start to fall over, cost preservation and/or inadequate closure provisioning generally mean that the protection and closure of waste sites become secondary considerations, leaving the potential threat of large areas of tailings and waste rock for someone else to clean up. Research data (Mine Closure Guideline, 2006) showed that almost 70 percent of mines that closed in Australia over the previous 25 years had unexpected and unplanned closures.

3. Unidentified and/or uncontrolled safety, health environmental or community impacts - a large amount of trust and goodwill is invested by politicians, regulators and other stakeholders (including the general public) on the veracity of safety, health, environmental and social impact submissions for new mining projects or expansions of existing projects. Where events and impacts occur that are contrary to predictions made in the project approvals and licensing submissions, the trust and goodwill is lost not only to the company involved, but to the entire industry, resulting in more onerous approvals processes and more severe compliance requirements.

\section{How does the reduction of waste management risk affect the licence to operate?}

Leading practice mining risk management identifies, amongst other health safety, environment and community/social risk issues, all the risk issues associated with mining waste management and puts effective controls in place to manage the potential risks throughout the operation and in the long term after closure.

Resources governance requires reliable and accurate mineral resource and ore reserve models in order to satisfy stock exchange reporting requirements, and hence provide shareholders with confidence that they are making a sound investment. Clearly, to support the mining industry's sustainability going forward, 
stakeholders investing trust and goodwill in future licences to operate also need reliable ecological, social and engineering models that can realistically predict the potential long-term impacts of waste.

However, there are a number of real issues that make this difficult when it comes to waste management:

1. The large degree of uncertainty, arising from the properties and behaviour of the waste itself, and from its interactions with various external meteorological and geophysical elements - climate, groundwater, seismicity, surface water, etc.

2. The lack of knowledge of the possible changes that will occur over time, particularly in the very long term after closure.

3. The short time available to gather the data, knowledge and experience required to formulate designs that are effective in controlling the various issues and interactions.

4. The absence of predictive models that can be confidently used to set performance targets and compliance levels, and to test the cost and risk control effectiveness of hard controls

(e.g. engineering controls) against solutions that commit to mitigate impacts if something untoward is noticed in the monitoring results.

In other words, when it comes to waste management design, we are often being asked to design something that will ensure that we will not cause harm, without the scientific and technical backing to do so.

The difficulty is increased further by the ever-present pressure to reduce the cost of waste management, and hence to increase the profitability of a project, and the tendency to exclude waste management and mine closure planning, which are seen as secondary issues because they do not contribute value, from operational and production planning considerations.

Therefore, a prerequisite of good waste risk management in support of the licence to operate is that all stakeholders must understand all the uncertainties involved, and must believe that the proposed solutions will effectively manage all risk issues at all times, including in the face of cost and other operational priorities. There are two approaches, both using predictive modelling with its inherent uncertainty, to demonstrate the potential issues and impacts:

1. In the first approach, the uncertainty is managed by a commitment to monitor for any untoward impacts, and to mitigate these if and when they occur.

2. The second approach attempts to eliminate the uncertainty regarding the veracity of data, analysis and magnitude or consequence of impact, by implementing hard controls (e.g. proven engineering measures) to eliminate or minimise the risk to a known and acceptable level.

As an example, acid rock drainage could be managed (first approach) by minimising infiltration, oxidation and seepage and committing to recover acidic seepage if a threat that it may impact an environmental or health value arises at some time. Using the second approach, an engineered underdrainage system would be provided under the waste dumps to collect leachate from the dumps, thereby eliminating the uncertainty of a health or environmental value being impacted.

The risk management approach adopted needs to consider the health and environmental values that may be impacted, as there is not necessarily commensurate value in using the second approach in all cases. The first approach tends to be used more frequently, with the preference being to defer the cost of environmental protection measures until closure, enhancing the net present value of the project.

But the danger is that things could go wrong with consequences far beyond those predicted at the start of the project, and it is noticeable that those mining companies that sincerely value their licence to operate are more frequently adopting the second approach. This approach is essentially aligned with the precautionary (or preventative) principle, i.e. if a threat of serious or irreversible damage to the environment or human health exists, engineering systems must be designed and installed to effectively eliminate or control the hazard.

In addition to improved risk management, it is also critical that leading practice planning integrates life of mine waste disposal, storage and closure planning into life of asset planning, to ensure that the waste management risk controls are appropriately and effectively designed, engineered, planned, monitored and reported from the earliest phases of a project onwards. 


\section{$5 \quad$ Is improved risk management enough?}

As with good ore reserves governance, risk management and growth, a mining company's organisational structure should also be able to demonstrate that its health, safety, environment and social governance includes effective waste management governance.

Mining companies that have knowledgeable technical professionals interacting at senior management levels are more likely to understand, appreciate, and pro-actively deal with the risks involved. These companies demonstrate accountability through knowledge at the highest levels, and demonstrate their commitment to sustainable development through actively supporting the development of the most appropriate controls irrespective of cost.

Companies that outsource technical issues through delegating accountability to lower level managers are at risk of not understanding the importance or potential magnitude of these issues through to the highest levels of management. Not only are the lower level managers unlikely to have the expertise or knowledge to understand the issues themselves, but they may unintentionally filter out the important information as it is passed upwards, as it is not good career management practice to give one's manager bad news. As a result, when things start to go wrong, the person holding ultimately accountability, i.e. the CEO, is unlikely to understand the issue or to appreciate just how serious it is.

BP's CEO Tony Hayward's early suggestion that the environmental impact from the BP Deepwater Horizon incident was likely to be "very, very modest" indicates that he was clearly not interacting with his technical experts, resulting in significant reputational damage to BP's license to operate.

\section{Conclusion}

The real value to the mining industry of leading-practice waste management lies in the adequacy and sufficiency of the industry's investment in its future licence to operate. If mining wastes and their associated risks are not managed correctly, or if we do not provide adequate financial assurances to close waste facilities in such a way that they do not have enduring long-term impacts, we will almost certainly leave future generations with major environmental, financial and social burdens, and hence seriously jeopardise the sustainability of the mining industry.

\section{References}

BHP Billiton (2010) BHP Billiton, Our Sustainability Framework, 2010, Accessed 20 July 2010, sourced from: http://www.bhpbilliton.com/bbContentRepository/docs/ourSustainabilityFramework.pdf

Mine Closure Guideline (2006) Australian Government Department of Industry, Tourism and Resources Leading Practice Sustainable Development Guideline on Mine Closure and Completion, October 2006.

Weekend Australian Financial Review July 17-18, 2010. 
